\title{
In silico Evaluation on the Inhibition Efficacy of Five Antivirals on SARS-CoV-2 Protease (COVID-19)
}

\author{
Vinod Palayoor Raphael ${ }^{\star}$, Shaju Kanimangalath Shanmughan \\ Department of Chemistry, Government Engineering College, Thrissur, Kerala, INDIA.
}

\begin{abstract}
Background: All over the world rigorous research attempts are going on to find a remedy for the spreading and prevention of the dreadful pandemic of $21^{\text {st }}$ century, the Coronavirus Disease (COVID-19). To discover an effective drug for curing and a preventive vaccine against this disease it will take more than one year. According to some medical practitioners certain antivirals which are used for other diseases can cure COVID-19. Aim: In the present investigation, five antivirals claiming to be effective therapeutic agents to mitigate the symptoms of COVID-19 were screened using computational docking studies on the main protease of coronavirus. Materials and Methods: Five antivirals considered are Favipiravir (FVR), Remdesivir (RMR), Hydroxychloroquine (HCQ), Lopinavir (LVR) and Ritonavir (RVR). The first three agents FVR, RMR and HCQ are used for the treatment of influenza, ebola and malaria respectively. Lopinavir and Ritonavir are the anti-HIV drugs. Favipiravir and Remdesivir are prod rugs and the active nucleotide metabolites (FVR-RTP and RMR-NTP) were taken for in silico docking investigations. AutoDockvina, EduPyMoL and Discovery Studio software's were used for the computational evaluation. Results: Among the studied molecules $\mathrm{HCO}$ displayed lowest score for the binding energy (-6.1 $\mathrm{kcal} / \mathrm{mol})$ and LPR showed the highest value $(-8.1 \mathrm{kcal} / \mathrm{mol})$ on SARS-CoV-2 protease. The binding energy of the antivirals on the protease follows the order $\mathrm{HCO}<\mathrm{RVR}$ $<$ RMR-NTP <FPR-RTP <LPR. Various interactions of the antivirals with the binding pocket of the protease are well explained using 2D and $3 D$ plots. Conclusion: Poor inhibition was noted for $\mathrm{HCO}$ in the protease binding pocket and hence the therapy using this drug for COVID-19 may not be effective. LPR displayed maximum value of binding capacity on the receptor. FPR-RTP interacted well on the protease with seven $\mathrm{H}$-bonds. RVR and RMR molecules also bound the receptor using strong favourable binding forces.
\end{abstract}

Key words: COVID-19, Docking, Inhibitor, Protease, Lopinavir, Ritonavir.

\section{INTRODUCTION}

Towards the end of 2019, China confirmed that the respiratory illness spreading quickly in the country is due to the virus SARSCoV-2 (Severe Acute Respiratory Syndrome Coronavirus 2). This virus spread from China to many countries in the world rapidly and it is designated as a pandemic disease (COVID-19) ${ }^{1}$ by World Health Organization on 11-March-2020. ${ }^{2}$ Majority of the infected patients had common symptoms such as fever, dry cough, tiredness, nasal congestion, sore throat or shortness of breath. ${ }^{3,4}$ Some developed fatal cases of viral pneumonia, respiratory and multi-organ failure. ${ }^{5,6}$ As on $26^{\text {th }}$ April 2020, more than 2 lakh people were killed and about 28 lakh were infected with Coronavirus-2. ${ }^{7}$ Affected countries declared temporary lock down to fight against this disease which impacted their socio-economic sectors badly.

Since there is no specific therapeutic formula to fight against this pandemic, the clinical treatment is mainly based on the symptoms of the patient. Pharmaceutical researchers across the world are hesitating to find out a potential cure for COVID-19. Even though phase II and phase III clinical trials of certain lead candidates and antibodies have been started, it may take 1-2 years to launch the medication in the market.
Submission Date: 16-04-2020; Revision Date: 17-07-2020; Accepted Date: 07-09-2020

DOI: 10.5530/ijper.54.4.197 Correspondence: Dr. Vinod P Raphael Assistant Professor, Department of Chemistry, Government Engineering College, Thrissur-680009, Kerala, INDIA.

Phone: +919287560416 E-mail: vinodpraphael@ gmail.com

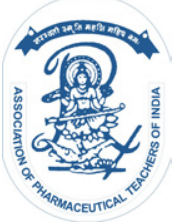

www.ijper.org 
US and China-based pharmaceutical companies claim that the Phase I and II clinical trials of mRNA- $1273^{8}$ and $\mathrm{Ad} 5-\mathrm{nCoV}^{9}$ vaccines are completed successfully just after 1-2 months the SARS-CoV-2 genetic code was reported ${ }^{10}$ (GenBank: MN908947.3). Many doctors claim that the clinical success rate of some antivirals and anti-inflammatory agents against the growth of Coronavirus-2 is high. For present treatment of COVID-19 patients some countries approved the existing antivirals such as Favipiravir ${ }^{11}$ (for influenza) ${ }^{12}$ Remdesivir $^{13}$ (for ebola), ${ }^{14}$ Hydroxychloroquine ${ }^{15}$ (for malaria, rheumatoid diseases), ${ }^{16}$ Lopinavir ${ }^{17}$ (antiHIV), ${ }^{18,19}$ Ritonavir $^{17}$ (anti-HIV) ${ }^{20,21}$ etc. The antiviral Interferon alfa- $2 \mathrm{~b}^{22}$ consisting of a mixture of several proteins $^{23}$ is one among the 30 medicines approved by China to treat COVID-19, which was first developed by $\mathrm{Cuba}^{24}$ in 1981 to fight against dengue fever and other viral infections. Actemra ${ }^{25,26}$ is an antiinflammatory (antibody) used to treat rheumatoid arthritis is also approved by China to treat ${ }^{27}$ COVID19. United States has given permission to conduct Phase II and III clinical trials with the antibody drug Kevzara $^{28,29}$ (anti-inflammatory). Indian Council for Medical Research (ICMR) has claimed that efficacy of Hydroxychloroquine is very high in mitigating the severe symptoms of COVID. ${ }^{30}$ Rigorous Investigations are conducted by the researchers to verify the efficiency of Hydroxychloroquine. Even though the death rate of COVID-19 is beyond expectation in countries like Italy, US, UK etc, India strongly took all measures to fight against this pandemic and hence reported lower fatalities. Doctors of Kerala (India) suggest anti-HIV drugs such as Lopinavir and Ritonavir as effective medications to fight against coronavirus after making clinical trials ${ }^{31}$ with the permission of ICMR. In this study we make suitable in silico trials of five popular antivirals against SARS-CoV-2 protease, which is the main target for drugs to fight against coronavirus. The main objective of the present investigation is to verify the effectiveness of the antivirals Favipiravir, Remdesivir, Hydroxychloroquine, Lopinavir and Ritonavir which are claimed to inhibit the growth of SARS-CoV-2 and to propose the most suitable medication among the selected antivirals using computational docking studies.

\section{MATERIALS AND METHODS SARS CoV-2 protease}

The genome of coronavirus consists of a large RNA chain which behaves like a messenger RNA when enter into a host cell and trigger the synthesis of polyproteins. ${ }^{32}$ These proteins are essential for the further multiplication of the viruses and during the replication and transcription steps protease molecules are created. The main role of the proteases is to cut the polyprotein chain into small fragments. The main protease of SARS-CoV-2 which is responsible for the dangers in China (PDB ID: 6lu7) ${ }^{33}$ can be considered as the important target for the drug molecules.

The X-ray crystallographic structure of COVID-19 main protein or SARS CoV-2 protease (6LU7) co-crystallised with the protein inhibitor N3 was retrieved from RSC Protein Data Bank. ${ }^{33}$ [PDB ID: 6lu7) (resolution: $2.6 \AA$; R-value free: 0.235$)]$. Figure $1 \mathrm{a}-\mathrm{d}$ depict the structure of protein with the protein inhibitor $\mathrm{N} 3$, protein binding site attached with the inhibitor, molecular structure of the inhibitor and the sequence of amino acids in the protease respectively. From Figure 1d it is evident that SARS-CoV-2 protease is made up of 306 amino acids. ${ }^{33}$

\section{Structures of antivirals}

Five antivirals namely Hydroxychloroquine (HCQ), Lopinavir (LPR), Ritonavir (RVR), Favipiravir (FPR) and Remdesivir (RMR) were considered for the in silico trials. The optimized geometries of the molecules or their metabolized products were used for the docking studies. The two dimensional structures of HCQ, LPR and RVR are shown in Figure 2. Favipiravir is a prodrug

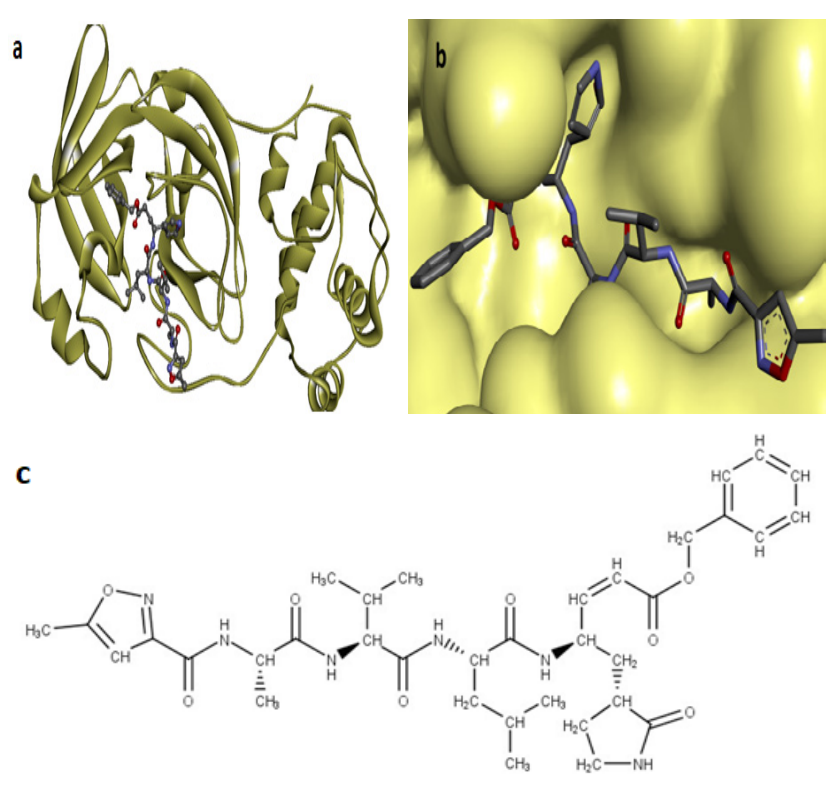

SGFRKMAFPSGKVEGCMVQVTCGTTTLNGLWLDDVVYCPRHVICTSEDMLNPNYEDLLIR60 KSNHNFLVQAGNVQLRVIGHSMQNCVLKLKVDTANPKTPKYKFVRIQPGQTFSVLACYNG120 SPSGVYQCAMRPNFTIKGSFLNGSCGSVGFNIDYDCVSFCYMHHMELPTGVHAGTDLEGN180 FYGPFVDRQTAQAAGTDTTITVNVLAWLYAAVINGDRWFLNRFTTTLNDFNLVAMKYNYE240 PLTQDHVDILGPLSAQTGIAVLDMCASLKELLQNGMNGRTILGSALLEDEFTPFDVVRQC300 SGVTFQ306

Figure. 1: a) Structure of SARS-CoV-2 protease co-crystallised with the inhibitor N3 b) Protein inhibitor N3 in the binding pocket c) Molecular structure of N3 d) The sequence of aminoacids in the protease 6 LU7. 
which when administered into the body metabolize into its active form favipiravir-ribofuranosyl-5'triphosphate $^{34}$ (FPR-RTP). The metabolized form of FPR is a nucleotide analogue molecule. For virtual screening studies Favipiravir-RTP is taken instead of Favipiravir (Figure 3). Similarly the antiviral Remdesivir is a prodrug when enter into the body changes into the biologically active form GS-441524 (a nucleoside analogue) which metabolize again via intracellular phosphorylation and form a Nucleotide Triphosphate analogue $^{35}$ (NTP) (Figure 4). This NTP (RMR-NTP) is supposed to interact with the COVID-19 main protease receptor.

\section{Docking studies}

Structure SARS-CoV-2 protease was prepared before the docking process using EduPyMol software (version 1.7.4). The co-crystallised water molecules and the protein inhibitor $\mathrm{N} 3$ were removed and added hydrogen atoms using EduPyMol. ${ }^{36}$ To define the binding pockets of the protein and its coordinates, DiscoveryStudio v1.6.1.0.15355 version software ${ }^{37}$ was used.

Virtual screening is a computational method used to identify the potential of various binding compounds in the protein target. Five antivirals were screened against SARS-CoV-2 protease using AutoDock vina ${ }^{38}$ after adding gasteiger charges. The drug ability of a candidate molecule can be predicted by analysing the score of the docking studies. Molecules which exhibit high binding energies with the target proteins and make more favourable interactions may successfully inhibit the growth of micro-organisms. After the docking process, characterization of the binding behaviour of

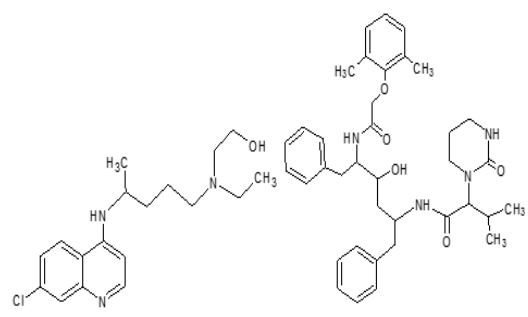

Hydroxychloroquine Lopinavir

Figure 2: Molecular structures of Hydroxychloroquine, Lopinavir and Ritonavir.

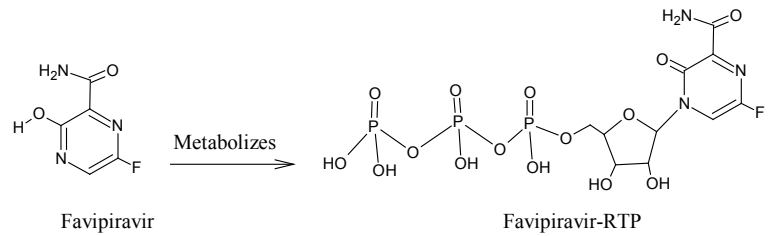

Figure 3: Structure of Favipiravir and its active form Favipiravir-RTP. the molecules with SARS-CoV-2 protease was done using Discovery Studio.

\section{RESULTS AND DISCUSSION}

Five antivirals were screened on COVID-19 protease using computational docking studies and the compounds were described based on their binding energy with the corresponding protein and the nature of interactions. All antiviral molecules displayed binding energies with SARS-CoV-2 protease ranging from -6.1 to $-8.1 \mathrm{kcal} /$ mol. The values of binding energy and the type of molecular interactions for the five compounds are given in Table 1. Different molecular interactions can be best viewed and analysed from 3D and 2D plots (Figure 5 and 6) obtained using Discovery Studio. The subsequent paragraphs describe the details of the nature and number favourable and non-favourable binding interactions taking place between the antiviral molecules and the binding pocket of SARS-CoV-2 protease receptor.

Hydroxychloroquine (HCQ) didn't exhibit very strong interaction with SARS-CoV-2 protease. The data of the docking results are given in Table 1 . The binding energy of HCQ with the protease was only $-6.1 \mathrm{kcal} / \mathrm{mol}$, indicates the moderate inhibition on the receptor. Only one conventional H-bond (length $2.05 \AA$ ) was formed between the peptide linkage $(\mathrm{C}=\mathrm{O})$ of Thr190 and the hydroxyl group of HCQ. The heterocyclic aromatic ring of HCQ interacted with the Cys145 residue of the protease through $\pi$-sulphur bond. Glu166 and Thr190 also formed two non-conventional $\mathrm{H}$-bonds with the $-\mathrm{CH}_{2}$ and $-\mathrm{CH}_{3}$ moieties of HCQ respectively. An unfavourable interaction of the type donor-donor was occurred between the hydroxyl group of HCQ and $\mathrm{N}-\mathrm{H}$ group of the residue Thr190. Since the binding energy of HCQ with the protease was low, it can be assumed that this is not an efficient inhibitor for the COVID-19 protease. In addition to one H-bond (Figure 6a) a few more interactions only existed between the HCQ and the protease. Amino acid residues Phe140, His163, His164, Met165, Pro168, Arg188 and Gln192 made weak van der Waals interactions with HCQ. On close examination of the 3D diagram (Figure 5a) it is clear that the contribution of HCQ to the left side of the binding pocket is very poor. The efficacy of this

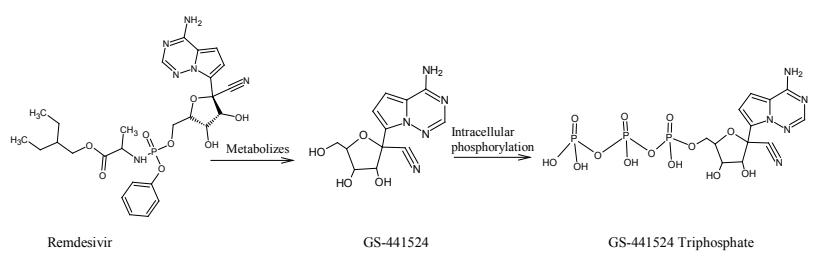

Figure 4: Structure of Remdesivir and its active metabolites. 
molecule to inhibit the growth of Coronavirus-2 has to be evaluated further by conducting more clinical trials. Ritonavir (RVR) was found to interact with the residues Glu143 and Gln189 of SARS-CoV-2 protease through H-bonds (lengths 2.29 and $2.37 \AA$ respectively). His41 residue made a $\pi$-cation bond with one of the benzene ring of Ritonavir. One $\pi$-sulphur bond and a non-conventional $\mathrm{H}$-bond were originated from the moiety Met165. Similarly Met49 residue formed one alkyl linkage and one $\pi$-alkyl bond with Ritonavir. One carbon H-bond was formed between Asn142 and one $\mathrm{C}=\mathrm{O}$ moiety of the molecule. Thr 25 and Thr26 formed $\pi$-sigma and carbon $\mathrm{H}$-bond respectively. $\pi$-alkyl hydrophobic bond was formed between the Pro168 and one of the thiazole ring of Ritonavir. Thr190 made a carbon $\mathrm{H}$-bond with the molecule. The binding energy of Ritonavir with the protease was found to be $-7.2 \mathrm{kcal} /$ mol. Tendency of RVR molecule to interact the binding pocket of the protease is clearly visible from the $3 \mathrm{D}$ and $2 \mathrm{D}$ interaction diagrams (Figure $5 \mathrm{~b}$ and $6 \mathrm{~b}$ ). RVR with its most favourable conformation fits well in the binding pocket. It is quite remarkable that this molecule utilizes all the aromatic and heterocyclic rings for the interaction with the binding pocket of COVID-19 protease. It can also be predicted that the two H-bonds established between the amino acid residues and the carbonyl and $\mathrm{N}-\mathrm{H}$ groups of RVR are fairly strong. RVR formed weak van der Waals forces with the residues Leu27, Thr45, Ser46, Tyr54, Phe40, Cys145, Asp187 and Arg188. The data of the computational screening studies are provided in Table 1.

Favipiravir-RTP (FPR-RTP) made various binding interactions with SARS-CoV-2 protease using favourable bonds. The data of virtual screening study is given in Table 1 . The binding energy of this molecule with the protease was $-7.7 \mathrm{kcal} / \mathrm{mol}$. Favourable interactions of FPR-RTP include seven H-bonds [Thr26(2.27 $\AA)$, Leu141(1.69 $\AA$ and 2.02

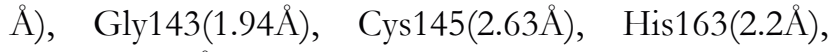
$\operatorname{Arg} 188(2.03 \AA)$ ], one $\pi$-alkyl (Cys145), one $\pi$-cation (His41) and two carbon H-bond (Pro165, Met168). Out of the seven conventional H-bonds, contribution by Favipiravir ring was two and the other five was from ribofuranosyl-triphosphate moiety. The ability of FPRRTP to produce six H-bonds makes it a good inhibitor for SARS-CoV-2 protease according to in silico studies. Though the binding energy and number of $\mathrm{H}$-bonds are appreciable for FPR-RTP-protease binding, 3D diagram (Figure $5 \mathrm{c}$ ) of binding surface shows little or poor interaction of triphosphate moiety of FPR-TRP with the right portion of the binding pocket. It is also evident from Figure 6c (2D plot) that out of seven

\begin{tabular}{|c|c|c|c|c|c|c|c|c|c|c|c|}
\hline 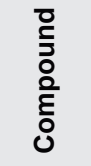 & 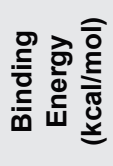 & $\begin{array}{l}\frac{0}{0} \\
\frac{1}{0} \\
\frac{0}{1}\end{array}$ & 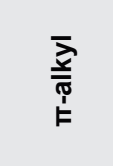 & $\begin{array}{l}\stackrel{5}{\frac{3}{5}} \\
\frac{0}{3} \\
\stackrel{1}{F}\end{array}$ & 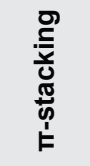 & 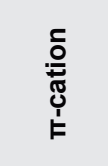 & 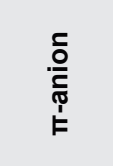 & $\begin{array}{l}\stackrel{\mathfrak{g}}{E} \\
\stackrel{0}{0} \\
\stackrel{p}{F}\end{array}$ & $\begin{array}{l}\frac{\omega}{0} \\
\frac{n}{\pi} \\
\frac{\pi}{\pi} \\
\frac{\pi}{3}\end{array}$ & 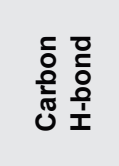 & $\frac{\bar{\lambda}}{\frac{\pi}{\alpha}}$ \\
\hline $\mathrm{HCQ}$ & -6.1 & Thr190 & - & Cys 145 & - & - & - & - & $\begin{array}{c}\text { Phe140, } \\
\text { His163, His164, } \\
\text { Met165, } \\
\text { Pro168, } \\
\text { Arg188, Gln192 }\end{array}$ & $\begin{array}{l}\text { Thr190, } \\
\text { Glu166 }\end{array}$ & - \\
\hline RVR & -7.2 & $\begin{array}{c}\text { Thr26, Gly143, } \\
\text { Gln189 }\end{array}$ & $\begin{array}{l}\text { Met49, } \\
\text { Pro168, }\end{array}$ & Met165 & - & His41 & Glu166 & Thr25 & $\begin{array}{l}\text { Leu27, Thr45, } \\
\text { Ser46, Tyr54, } \\
\text { Phe40, Cys145, } \\
\text { Asp187, Arg188 }\end{array}$ & $\begin{array}{l}\text { Asn142, } \\
\text { Met165, } \\
\text { Glu166, } \\
\text { Glu189, } \\
\text { Thr180 }\end{array}$ & Met49 \\
\hline $\begin{array}{l}\text { FPR- } \\
\text { RTP }\end{array}$ & -7.7 & $\begin{array}{c}\text { Thr26, } \\
\text { Leu141(2No.s), } \\
\text { Gly143, } \\
\text { Cys145, } \\
\text { His163, Arg188 }\end{array}$ & Cys145 & - & - & His41 & - & - & $\begin{array}{l}\text { Leu27,Met49,P } \\
\text { he140,Ser144, } \\
\text { Met165, Pro168 }\end{array}$ & $\begin{array}{l}\text { Pro165, } \\
\text { Pro168 }\end{array}$ & - \\
\hline $\begin{array}{l}\text { RMR- } \\
\text { NTP }\end{array}$ & -7.4 & $\begin{array}{c}\text { Thr26 (2no.s), } \\
\text { Gly143, } \\
\text { Glu166, } \\
\text { Ser46 (2no.s) }\end{array}$ & Met49 & Cys 145 & - & Glu166 & - & His41 & $\begin{array}{c}\text { Leu27, Phe140, } \\
\text { Cys 145, } \\
\text { His163, His164, } \\
\text { Gln189 }\end{array}$ & Gln189 & Met149 \\
\hline LPR & -8.1 & $\begin{array}{l}\text { Glu166, } \\
\text { Gln189 }\end{array}$ & $\begin{array}{l}\text { His41, } \\
\text { Met49 }\end{array}$ & Met165 & His41 & - & - & - & $\begin{array}{c}\text { Phe140, } \\
\text { Cys145, } \\
\text { His163, } \\
\text { His164,His172 }\end{array}$ & Met165 & Leu27 \\
\hline
\end{tabular}




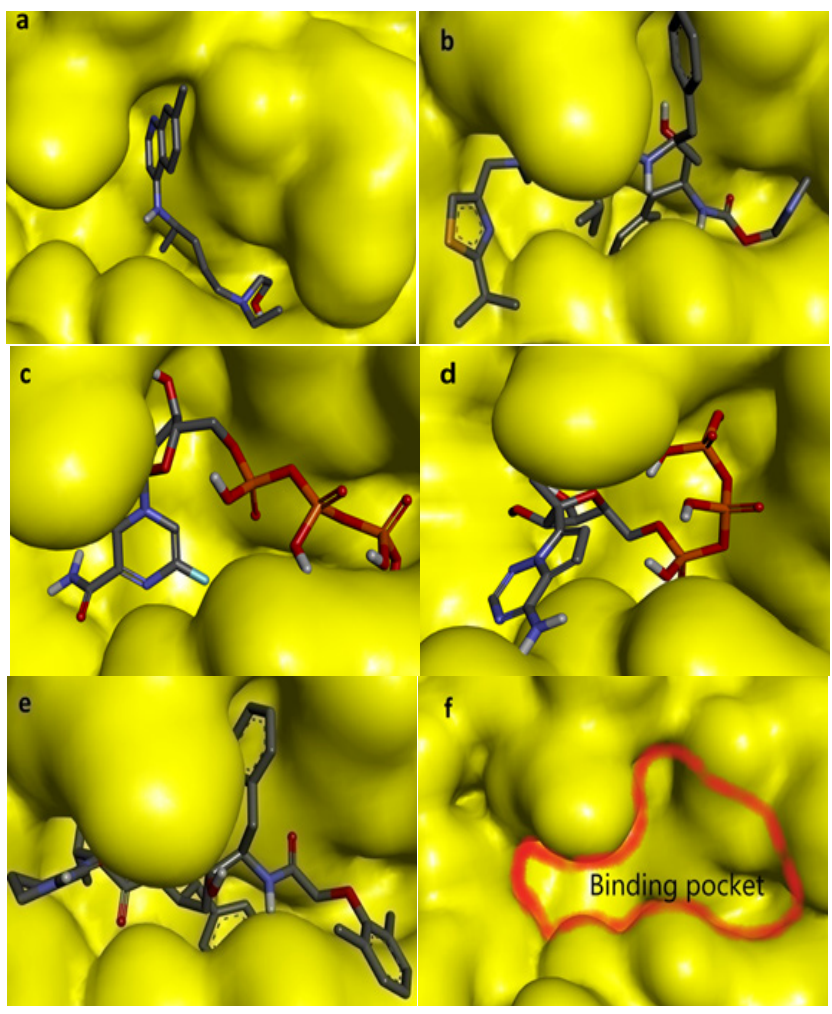

Figure 5: 3D interaction diagrams of SARS-CoV-2 protease with the antivirals/metabolites a) Hydroxychloroquine b) Ritonavir c) Favipiravir-RTP d) Remdesivir-NTP and e) Lopinavir. f) The binding pocket of the protease.

H-bonds, six are formed between the two heterocyclic rings of FPR-RTP and left portion of the binding site of the protease. Leu27, Met49, Phe140, Ser144, Met165, Pro168 are the amino acid residues which established van der Waals interaction with FPR-TRP. In general, the cyclic parts of FPR-RTP interact well with one section of binding pocket of COVID-19 protease. One unfavourable interaction was also displayed by this molecule between Thr190 of protease and terminal O-H group of triphosphate.

According to virtual screening studies, the binding energy of the metabolized form of the antiviral Remdesivir (RMR-NTP) with the SARS-CoV-2 protease was $-7.4 \mathrm{kcal} / \mathrm{mol}$. The details of the docking results are displayed in Table 1. RMR-NTP established six conventional H-bonds with Thr26 (2no.s), Ser46 (2no.s), Gly143 and Glu166. Out of the six H-bonds, two were donated by the ligand's hydroxyl groups and one originated from the $\mathrm{N}-\mathrm{H}_{2}$ group. Oxygen atom of the ribose ring, one of the $\mathrm{P}=\mathrm{O}$ bond and $\mathrm{N}$ atom of the heterocyclic ring of the RMR-NTP acted as H-bond acceptors from the amino acid residues Gly143, Glu166 and Ser46 respectively. One unfavourable interaction was also shown by RMR-NTP withHis41 (N-P donor-

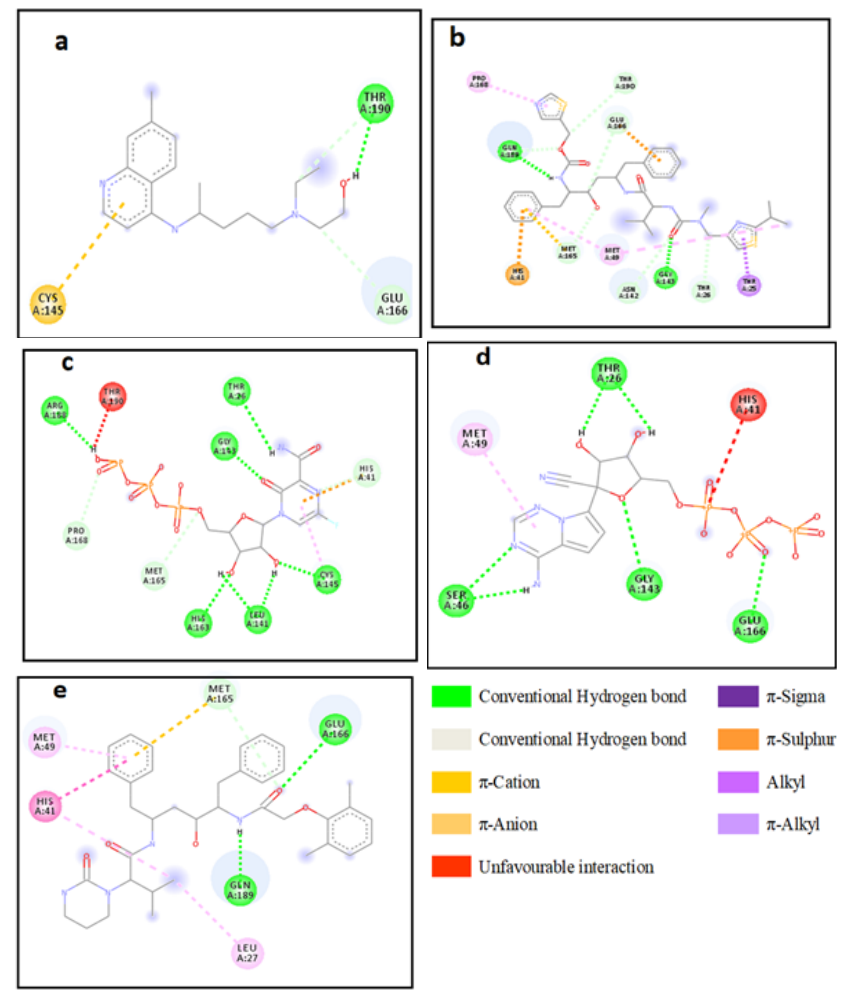

Figure 6: 2D plots $^{*}$ showing the main interactions of SARS-CoV-2 protease with the antivirals/metabolites a) Hydroxylchloroquine b) Ritonavir c) Favipiravir-RTP d) Remdesivir-NTP and e) Lopinavir ( ${ }^{*}$ van der Waals interactions are omitted for clarity).

donor type). Leu27, Phe140, Cys145, His163, His164 and $\mathrm{Gln} 189$ residues of the protease weakly interacted with RMR-NTP (van der Waals interaction). 2D interaction diagram of RMR-NTP with the protease is given in Figure 6d. 3D binding pocket of protease loaded with RMR-NTP is depicted in Figure 5d. From the $3 \mathrm{D}$ diagram one can confirm that the binding site of the protease is reasonably occupied by RMR-NTP metabolite.

The antiviral Lopinavir (LPR) efficiently inhibited the protease by making two $\mathrm{H}$-bonds with the amino acid residues Glu166 and Gn189. Binding energy of Lopinavir with SARS-CoV-2 protease was $-8.1 \mathrm{kcal} /$ mol. Three dimensional protein surface diagram containing the ligand in the most suitable conformation clearly portraits the enhanced interaction of Lopinavir with SARS-CoV-2 protease. The molecule fitted well in the binding pocket of the protease (Figure 5e). The nature of interactions of Lopinavir with the amino acid residues present in the binding site of the protease can be visualized from 2D interaction plot (Figure 6e). The residue Glu166 acted as $\mathrm{H}$-bond donor $(\mathrm{N}-\mathrm{H})$ to the molecule while Gln189 accepted H-bond donated by $\mathrm{N}-\mathrm{H}$ group of LPR. Three hydrophobic interactions 
was established between the Lopinavir and amino acid residues of the protease Leu27 (alkyl-alkyl), His41 $(\pi$-alkyl) and Met49 ( $\pi$-alkyl).A $\pi$-stacked interaction was formed between the imidazole ring of His41 and one of the benzene rings of Lopinavir. Met165 residue interacted with the Lopinavir with two bonds; first one is the $\pi$-sulphur linkage with one benzene ring and second one is carbon $\mathrm{H}$-bond with $\mathrm{C}=\mathrm{O}$ of Lopinavir. Weak van der Waals bonds were also established between the amino acid residues Phe140, Cys145, His163, His164, His172 and the protease. Table 1 shows the results of docking studies of Lopinavir with SARS$\mathrm{CoV}-2$ protease. Though the number of $\mathrm{H}$-bonds between the protease and Lopinavir is only two, other favourable interactions make the molecule an efficient inhibitor of COVID-19 protein.

\section{CONCLUSION}

Five antiviral drugs Favipiravir, Remdesivir, Hydroxychloroquine, Lopinavir and Ritonavir were screened using computational docking studies on SARS-CoV-2 protease receptor. The binding energy of the antivirals on the protease follows the order HCQ $<$ RVR $<$ RMR-NTP $<$ FPR-RTP $<$ LPR. From the in silico studies it may be concluded that except HCQ, all the antivirals fairly inhibited COVID-19 protease with large positive interactions. Metabolized products of Favipiravir (FPR-RTP) and Remdesivir (RMR-NTP) displayed seven and six conventional $\mathrm{H}$-bonds with the binding pocket of the protease and hence can be considered as effective inhibitors. 3D surface plot of the protease with RMR-NTP depicts the perfect fit nature of this metabolized product in the binding pocket. Ritonavir and Lopinavir exhibited only two H-bonds with the receptor and shown binding energies of -7.2 and $-8.1 \mathrm{kcal} / \mathrm{mol}$ with the protease respectively. The combinatorial therapy using Ritonavir and Lopinavir may be fruitful against COVID-19 as suggested by some medical practitioners.

\section{ACKNOWLEDGEMENT}

Authors are thankful to the Heads, Department of Chemistry and Department of Chemical Engineering, Government Engineering College, Thrissur, Kerala, India for giving support to do this work.

\section{CONFLICT OF INTEREST}

The authors declare no conflict of interest.

\section{ABBREVIATIONS}

SARS-CoV-2: Severe Acute Respiratory Syndrome Coronavirus 2; COVID-19: CORONAVIRUS DISEASE-19; HIV: Human Immunodeficiency Virus; ICMR: Indian Council for Medical Research; HCQ: Hydroxychloroquine; LPR: Lopinavir; RVR: Ritonavir; FPR: Favipiravir; RMR: Remdesivir; FPR-RTP: Favipiravir-Ribofuranosyl-5'-Triphosphate; RMRNTP: Remdesivir-Nucleotide Triphosphate; PDB: Protein Data Bank

\section{REFERENCES}

1. World Health Organization [www.who.int]. Geneva: WHO Technical Guidance. 2020. Available from:https://www.who.int/emergencies/diseases/ novel-coronavirus-2019/technical-guidance/naming-the-coronavirusdisease-(covid-2019)-and-the-virus-that-causes-it

2. World Health Organization. Geneva: WHO Technical Guidance. 2020. Available from: https://www.who.int/dg/speeches/detail/who-directorgeneral-s-opening-remarks-at-the-media-briefing-on-covid-19--13-april-2020

3. Centers for Disease Control and Prevention. CDC Symptoms of coronavirus. 2020. Feb 10] Available from:https://www.cdc.gov/coronavirus/2019-ncov/ symptoms-testing/symptoms.html)

4. World Health Organization. Geneva: WHO Newsroom, Q and A on coronaviruses (COVID-19). 2020. Available from:(https://www.who.int/newsroom/q-a-detail/q-a-coronaviruses)

5. Hui DS, Azhar EI, Madani TA, Ntoumi F, Kock R, Dar O, et al. The continuing 2019-nCoV epidemic threat of novel coronaviruses to global health: The latest 2019 novel coronavirus outbreak in Wuhan, China. Int J Infect Dis. 2020;91:264-6. doi:10.1016/j.ijid.2020.01.009

6. Indian Council of Medical Research, Press release. Available from:(www. icmr.gov.in/media.html)

7. BBC News. Coronavirus pandemic: Tracking world outbreak. 2020. Available from:https://www.bbc.com/news/amp/world-51235105

8. U.S. National Laboratory of Medicine. Safety and Immunogenicity Study of 2019-nCoV Vaccine (mRNA-1273) for Prophylaxis SARS CoV-2 Infection. 2020. Available from: https://www.clinicaltrials.gov/ct2/show/NCT04283461

9. Liu A, Fierce P. Vaccine Angus Liu, China's Can Sino Bio advances COVID-19 vaccine into phase 2 on preliminary safety data. 2020. [updated $2020 \mathrm{Apr} 10$ ]. Available from:https://www.fiercepharma.com/vaccines/china-s-cansino-bioadvances-covid-19-vaccine-into-phase-2-preliminary-safety-data

10. Wu F, Zhao S, Yu B, ChenYM, Wang W, et al. A new coronavirus associated with human respiratory disease in China. Nature. 2020;579(7798):265-9. https://doi.org/10.1038/s41586-020-2008-3

11. Du YX, Chen XP. Favipiravir pharmacokinetics and concerns about clinical trials for 2019-nCoV infection. Clin Pharmacol Thers. 2020. doi:10.1002/ cpt.1844. PMID 32246834

12. Shiraki K, Daikoku T. Favipiravir, an anti-influenza drug against lifethreatening RNA virus infections. Pharmacol Ther. 2020;209:107512. doi: 10.1016/j.pharmthera.2020.107512.

13. Doug B. Medscape. 2020. [https://www.medscape.com]. Remdesivir under study as treatment for novel coronavirus [updated 2020 Feb 7]Available from:https://www.medscape.com/viewarticle/924964

14. Warren TK, Jordan R, Lo MK, Ray AS, Mackman RL, Soloveva V, et al. Therapeutic efficacy of the small molecule GS-5734 against Ebola virus in rhesus monkeys. Nature. 2016;531(7594):381-5. doi:10.1038/nature17180.

15. Cortegiani A, Ingoglia G, Ippolito M, Giarratano A, Einav S. A systematic review on the efficacy and safety of chloroquine for the treatment of COVID-19. J Crit Care. 2020. doi:10.1016/j.jcrc.2020.03.005. PMID 32173110.

16. World Health Organization Model List of Essential Medicines, $21^{\text {st }}$ List, 2019. Geneva: World Health Organization. Licence: CC BY-NC-SA 3.0 IGO. 2019. Available from: https://apps.who.int/iris/bitstream/handle/10665/325771/ WHO-MVP-EMP-IAU-2019.06-eng.pdf?sequence=1 andisAllowed=y 
17. Cao B, Wang Y, Wen D, Liu W, Wang J, Fan MS, et al. A Trial of LopinavirRitonavir in Adults Hospitalized with Severe Covid-19. N Engl J Med. 2020 doi:10.1056/NEJMoa2001282. doi:10.1056/NEJMoa2001282.

18. Capparelli E, Holland D, Okamoto C, Gragg B, Durelle J, Marquie BJ, et al. Lopinavir concentrations in cerebrospinal fluid exceed the $50 \%$ inhibitory concentration for HIV. AIDS. 2005;19(9):949-52.

19. Drug Bank Drug Bank id: DB01601(EXPT00388). [https://www.drugbank.ca] Available from: https://www.drugbank.ca/drugs/DB01601

20. Centers for Disease Control and Prevention. HIV Surveillance: United States, Weekly report. 2011;360(21):689-93. [www.cdc.gov] Available from: www. cdc.gov/mmwr/preview/mmwrhtml/mm6021a2.htm

21. Drug Bank Drug Bankid. DB00503(APRD00312). 2009. [https://www drugbank.ca] Available from:https://www.drugbank.ca/drugs/DB00503

22. Tom O'C. Cuba uses wonder drug to fight coronavirus around the world despite U.S. sanctions. Newsweek. 2020. Available from: https://www. newsweek.com/cuba-drug-fight-coronavirus-us-sanctions-1493872

23. Nagata S, Taira H, Hall A, Johnsrud L, Streuli M, Joseph E, et al. Synthesis in E. coli of a polypeptide with human leukocyte interferon activity. Nature. 1980; 284(5754):316-20. doi:10.1038/284316a0

24. Weissmann C. Recombinant Protein Drugs, $1^{\text {st }}$ edn, Switzerland: Springer Nature. 2001. doi:10.1007/978-3-0348-8346-7_1. ISBN 978-3-0348-8346-7.

25. Venkiteshwaran A. Tocilizumabm. Abs. 2009;1(5):432-8. doi:10.4161/ mabs.1.5.9497

26. Media release Roche. Roche gains FDA approval for new subcutaneous formulation of ACTEMRA for use in adult patients living with moderately to severely active rheumatoid arthritis. 2013. [www.roche.com]Available from: https://www.roche.com/dam/jcr:b7b1d38c-050e-4603-a663-5edf3e3e527d/ en/med-cor-2013-10-22-e.pdf

27. Roxanne L, John M. China approves use of Roche drug in battle against coronavirus complications. Reuters. 2020. Available from: https://www.reuters. com/article/us-health-coronavirus-china-roche-hldg/china-approves-use-ofroche-drug-in-battle-against-coronavirus-complications-idUSKBN20ROLF

28. European Medicines Agency. Kevzara: Authorisation details. [www.ema. europa.eu/en]. Available from: https://www.ema.europa.eu/en/medicines/ human/EPAR/kevzara
29. Claude S. Northwell Health Initiates Clinical Trials of 2 COVID-19 Drugs. Long Island Press. 2020. [www.longislandpress.com]. Available from: .https://www. longislandpress.com/2020/03/21/northwell-health-initiates-clinical-trials-of-2covid-19-drugs/

30. Indian Council of medical Research. Recommendation for empiric use of hydroxy-chloroquine for prophylaxis of SARS-CoV-2 infection. 2020. [www. icmr.nic.in]Available from: https://icmr.nic.in/sites/default/files/upload_ documents/HCQ_Recommendation_22March_final_MM_V2.pdf

31. The economic times [https://economictimes.indiatimes.com]. Kerala: British national given HIV antiretroviral drugs to treat coronavirus now tests negative 2020 Mar 26. Available from: https://economictimes.indiatimes.com/news/ politics-and-nation/kerala-british-national-given-hiv-antiretroviral-drugs-totreat-covid-19-now-tests-negative/articleshow/74816741.cms?from=mdr

32. Coronavirus protease, Educational Portal of RCSB Protein Data Bank. 2020. Available from:https://pdb101.rcsb.org/motm/242

33. Protein Data Bank. PDB ID: 6lu7. 2020 [www.rcsb.org]. Available from: https://www.rcsb.org/structure/6lu7

34. Smee DF, Hurst BL, Egawa H, Takahashi K, Kadota T, Furuta Y. Intracellular metabolism of favipiravir (T-705) in uninfected and influenza A (H5N1) virusinfected cells. J Antimicrob Chemother. 2009;64(4):741-46. doi:10.1093/jac/ dkp274

35. Aesop C, Oliver LS, Thomas B, Lijun Z, Jie X, Jennifer EV, et al. Synthesis and antiviral activity of a series of 1'-substituted 4-aza-7,9-dideazaadenosine C-nucleosides. Bioorg Med Chem Lett. 2012;22(8):2705-7. https://doi. org/10.1016/j.bmcl.2012.02.105

36. The PyMOL Molecular Graphics System Software Version 1.2r3pre, Schrödinger. LLC.

37. Dassault Systèmes BIOVIA, Discovery Studio Software version v1.6.1.0.15355, San Diego: Dassault Systèmes.

38. Trott O, Olson AJ. Auto DockVina: Improving the speed and accuracy of docking with a new scoring function, efficient optimization and multithreading. J Comput Chem. 2010;31(2):455-61.

\section{PICTORIAL ABSTRACT}

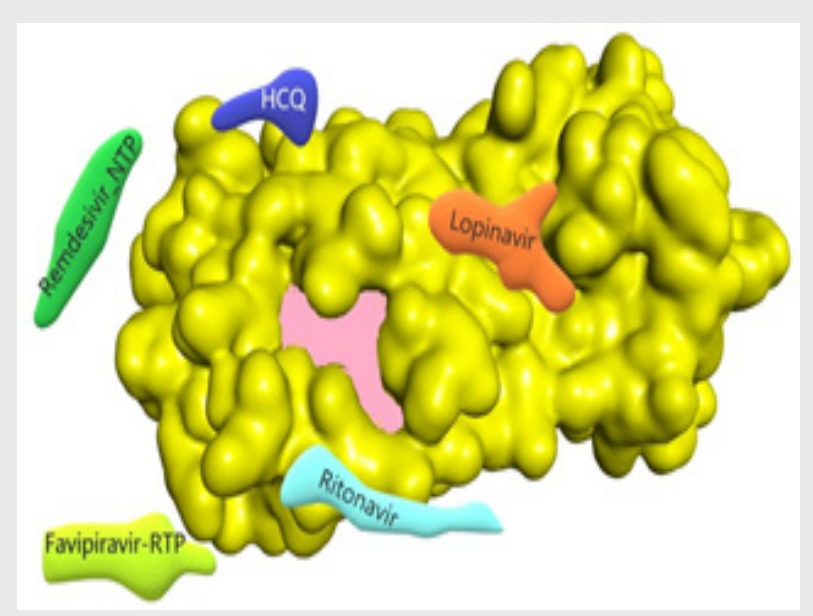

\section{SUMMARY}

In the present investigation in silico screening of five antivirals Favipiravir (FVR), Remdesivir (RMR), Hydroxychloroquine (HCQ), Lopinavir (LVR) and Ritonavir (RVR) were conducted on SARS-CoV-2 protease using docking software's. Potencies and nature of the interactions with the protease of these antivirals claiming to be effective to mitigate the symptoms of COVID-19 are revealed by this study. Metabolized product of Remdesivir and Favipiravir were taken for docking studies instead of RVR and FVR. According to the computational investigation, $\mathrm{HCO}$ molecule bound on the receptor with very low and weak interactions. The highest interaction was observed between the protease and LPR molecule. As suggested by some medical practitioners the combinatorial therapy using the anti-HIV drugs LPR and RVR may be effective against coronavirus. Metabolized product of FVR established seven $\mathrm{H}$-bonds with the receptor. Structural characteristics of all antivirals and their interaction with the binding pocket of protease were well explained in this paper. 


\section{About Authors}

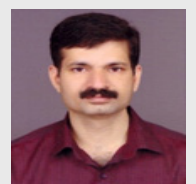

Dr. Vinod P. Raphael is currently working as Assistant Professor, in the Chemistry department, Government Engineering College, Thrissur, Kerala, India. He secured his M. Phil and Ph.D degrees from the University of Calicut, Kerala. His research areas of interests are Schiff base Co-ordination compounds, pharmaceutical chemistry, electrochemical research and corrosion inhibition of natural and synthetic compounds. He is currently working in the area of computational evaluation of the drug ability of natural product analogues.

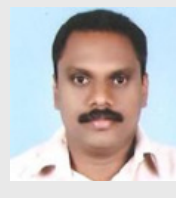

Dr. Shaju K S is currently working as Assistant Professor, Department of Chemistry, Government Engineering College, Thrissur, Kerala, India. He took his M. Phil and Ph.D degrees from the University of Calicut, Kerala. He is an M. Tech degree holder and has a vast experience in industrial catalysis. He secured this degree with the second rank from Cochin University of Science and Technology, Kerala, India. He is an expert in the area of corrosion inhibitors. Now he focuses on the synthesis of novel polynuclear aromatic compounds and checking their efficacy to inhibit enzymes and proteins responsible for various diseases.

Cite this article: Raphael VP, Shaju KS. In silico Evaluation on the Inhibition Efficacy of Five Antivirals on SARSCoV-2 Protease (COVID-19). Indian J of Pharmaceutical Education and Research. 2020;54(4):1031-8. 